\title{
Calcium glycerophosphate supplemented to soft drinks reduces bovine enamel erosion
}

\author{
Carolina Silveira BARBOSA ${ }^{1}$, Lia Guimarães MONTAGNOLLI ${ }^{1}$, Melissa Thiemi KATO², Fábio Correia SAMPAIO ${ }^{3}$, \\ Marília Afonso Rabelo BUZALAF ${ }^{4}$
}

\author{
1- DDS, Bauru School of Dentistry, University of São Paulo, Bauru, SP, Brazil. \\ 2- DDS, MSc, PhD, Bauru School of Dentistry, University of São Paulo, Bauru, SP, Brazil. \\ 3- DDS, MSc, PhD, Professor, Discipline of Clinic for Preventive Dentistry, Health Sciences Center, Federal University of Paraíba, João Pessoa, PB, Brazil. \\ 4- DDS, MSc, PhD, Full Professor, Discipline of Biochemistry, Department of Biological Sciences, Bauru School of Dentistry, University of São Paulo, Bauru, \\ SP, Brazil.
}

Corresponding address: Profa. Dra. Marília Afonso Rabelo Buzalaf - Faculdade de Odontologia de Bauru, Universidade de São Paulo - Departamento de Ciências Biológicas - Al. Octávio Pinheiro Brisolla, 9-75 - Bauru - SP - 17012-901 - Brasil

- Phone: + 551432358346 - Fax + 551432262076 - e-mail: mbuzalaf@fob.usp.br

Received: September 17, 2010 - Modification: August 7, 2011 - Accepted: August 25, 2011

\section{ABSTRACT}

bjective: This in vitro study evaluated the effect of calcium glycerophosphate (CaGP)
supplemented to soft drinks on bovine enamel erosion. Material and methods: Four $\mathrm{pH}-$
cycles were performed, alternating demineralization by the beverage and remineralization
in artificial saliva. Results: Mean wear $( \pm S D, \mu \mathrm{m})$ was $7.91 \pm 1.13,7.39 \pm 1.01,7.50 \pm 0.91$
and $5.21 \pm 1.08$ for Coca-Cola ${ }^{\mathrm{TM}}$ without CaGP or containing CaGP at $0.1,1.0$ or $2.0 \mathrm{mM}$,
respectively, while no wear was detected for CaGP at 5.0 and $10.0 \mathrm{mM}$. Corresponding
figures for Sprite Zero $\mathrm{T}_{\mathrm{TM}}$ without CaGP or containing CaGP at $0.1,1.0,2.0,5.0$ or 10.0
$\mathrm{mM}$ were $8.04 \pm 1.30,7.84 \pm 0.71,7.47 \pm 0.80,4.96 \pm 0.81,3.99 \pm 0.10$ and $1.87 \pm 0.12$,
respectively. Conclusion: Supplementation of both beverages with CaGP seems to be an
alternative to reduce their erosive potential.

Key words: Calcium glycerophosphate. Soft drinks. Enamel. Erosion.

\section{INTRODUCTION}

In the last decades, a reduction in caries prevalence has been observed ${ }^{15}$. Thus, teeth are maintained for a longer time in the oral cavity, which turns them more susceptible to the development of other kinds of lesions, such as erosion. Additionally, the excessive consumption of soft drinks and beverages with low $\mathrm{pH}$ has increased considerably in the last years, as a result of new dietary habits and distinct life styles of the population in general ${ }^{10}$. In Brazil, between 1995 and 2003, the consumption of soft drinks increased $490 \%{ }^{9}$.

In order to reduce the erosive potential of soft drinks, it has been proposed to supplement them with ions that are relevant for the formation of hydroxyapatite, such as calcium, phosphate and fluoride $2,6,8$. Recently, it was observed that supplementation of Sprite Zero $^{\text {Tm }}$ with low calcium concentration ( $1 \mathrm{mM}$ ) was able to significantly reduce the wear of bovine enamel, regardless of the presence of fluoride ${ }^{13}$.

It has been reported that calcium glycerophosphate (CaGP) reduces the acid dissolution of enamel ${ }^{7}$. This has led to its addition into toothpastes which improved their cariostatic effects $^{5,14}$. The cariostatic properties of CaGP have been demonstrated in various in vivo and in vitro studies. Several mechanisms have been suggested, including plaque-pH buffering, increase of plaque calcium and phosphate levels and direct interaction with dental mineral ${ }^{12}$. However, to the best of our knowledge, there is no information in the literature regarding the supplementation of soft drinks with CaGP aiming to reduce their erosive potential. Considering that CaGP contains both calcium and phosphate, the aim of the present study was to evaluate if the supplementation of Coca-Cola ${ }^{T m}$ and Sprite Zero $^{\text {Tm }}$ with different concentrations of CaGP would be able to reduce the erosive potential of these soft drinks. 


\section{MATERIAL AND METHODS}

\section{Enamel samples preparation}

Two hundred and forty enamel samples (4x4x3 $\mathrm{mm}$ ) were prepared from extracted sound bovine incisors. One sample was cut from each crown using ISOMET Low Speed Saw cutting machine (Buehler Ltda., Lake Bluff, IL, USA) and two diamond disks (Extec Corp., Enfield, CT, USA), which were separated by a 4-mm diameter spacer. The enamel surface was ground flat with watercooled carborundum discs (320-, 600- and 1200grit $\mathrm{Al}_{2} \mathrm{O}_{3}$ papers; Buehler) and polished with felt paper wet by diamond spray ( $1 \mu \mathrm{m}$; Buehler). This procedure resulted in removal of about $100 \mu \mathrm{m}$ of enamel in depth.

After the preparation, the surface microhardness of the samples was determined by performing five indentations (Knoop diamond, 25 g, 5 s, HMV-2000; Shimadzu Corporation, Tokyo, Japan) for selection and randomized distribution of the specimens. Enamel samples with mean microhardness of 354 KHN ( $\pm 10 \%)$ were randomly distributed into 12 groups ( $n=20$ per group), which differed according to the type of soft drink tested (Coca-Cola ${ }^{\text {mm }}$ or Sprite Zero $\left.^{\mathrm{Tm}}\right)$ and also in respect to the concentration of CaGP added to these soft drinks $(0,0.1,1.0,2.0$, 5.0 or $10.0 \mathrm{mM}$ ). These concentrations were chosen because they showed good results in previous studies when calcium or phosphate salts were added separately to citric acid ${ }^{2,3}$. After the addition of CaGP or not, the $\mathrm{pH}$ of the soft drinks was measured.

Two layers of nail polish were applied on half of the surface of the enamel in order to maintain reference surfaces for lesion depth determination.

\section{Erosive pH-cycling}

The blocks were submitted to $4 \mathrm{pH}$ cycles under agitation in only one day. Each cycle consisted of demineralization by immersion in pure or modified Coca-Cola ${ }^{\mathrm{TM}}$ or Sprite Zero ${ }^{\mathrm{TM}}$ (Coca-Cola Company, Spal, Porto Real, RJ, Brazil) for $10 \mathrm{~min}$ (30 mL per sample) at $25^{\circ} \mathrm{C}$, followed by a rinse in deionized water and remineralization in artificial saliva (30 $\mathrm{mL}$ ) during $59 \mathrm{~min}$ at $37^{\circ} \mathrm{C}^{11}$. The composition of the artificial saliva was: calcium $1.5 \mathrm{mmol} \mathrm{L-1}$, phosphate $0.9 \mathrm{mmol} \mathrm{L}^{-1}, \mathrm{KCl} 150 \mathrm{mmol} \mathrm{L}^{-1}$ in TRIS buffer $0.1 \mathrm{~mol} \mathrm{~L}^{-1}, \mathrm{pH} 7.0$, containing $0.03 \mu \mathrm{g} / \mathrm{mL}$ fluoride ${ }^{16}$.

\section{Wear assessment}

After the $\mathrm{pH}$ cycling, the enamel wear was determined in relation to the reference surfaces with a contact profilometer (Hommel Tester T 1000, Hommelwerke, VS, Schwenningen, Germany). The reference areas (half of the surface), which remained protected by nail varnish over the whole test period, were carefully cleaned with acetone- soaked cotton wool. Five readings were performed on each slab and the average wear depth was calculated (micrometers). These profilometric traces were taken from the reference surface, across the exposed surface.

\section{Statistical analysis}

The software GraphPad Prism 4 version 4.0 for Windows (GraphPad Software, San Diego, CA, USA) was checked. Initially, normality and homogeneity of the data were used, using Kolmogorov-Smirnov and Bartlett tests, respectively. For Coca-Cola ${ }^{\mathrm{Tm}}$, data were tested by ANOVA and Tukey's test, while for Sprite Zero ${ }^{\mathrm{TM}}$, Kruskal-Wallis and Dunn's test were used. The significance level was set at $5 \%$.

\section{RESULTS}

Table 1 shows the changes in $\mathrm{pH}$ of the beverages after the addition of CaGP. The pH of Coca-Cola ${ }^{\mathrm{Tm}}$ and Sprite Zero $^{\text {TM }}$ before the addition of CaGP was 2.72 and 2.87 , respectively. For both drinks, it remained almost constant with the addition of CaGP up to $2.0 \mathrm{mM}$. However, for the addition of CaGP at 5.0 and $10.0 \mathrm{mM}$, the $\mathrm{pH}$ increased to 4.37 and 5.29, respectively, for Coca-Cola ${ }^{\mathrm{m}}$ and to 3.20 and 3.47 ,

Table 1- Mean wear $( \pm S D, \mu m)$ of bovine enamel blocks treated with Coca-Cola ${ }^{\mathrm{TM}}$ or Sprite Zero ${ }^{\mathrm{TM}}$ supplemented with different concentrations of calcium glycerophosphate (CaGP) and $\mathrm{pH}$ of the beverages

\begin{tabular}{ccc}
\hline $\begin{array}{c}\text { CaGP } \\
\text { concentrations } \\
(\mathrm{mM})\end{array}$ & \multicolumn{2}{c}{$\begin{array}{c}\text { Mean wear } \\
(\mathrm{pH})\end{array}$} \\
\hline & Coca-Cola $^{\mathrm{TM}}$ & Sprite Zero $^{\mathrm{TM}}$ \\
0 (control) & $7.91 \pm 1.13^{\mathrm{a}}$ & $8.04 \pm 1.30^{\mathrm{a}}$ \\
& $(2.72)$ & $(2.87)$ \\
0.1 & $7.39 \pm 1.01^{\mathrm{a}}$ & $7.84 \pm 0.71^{\mathrm{a}}$ \\
& $(2.36)$ & $(2.93)$ \\
1.0 & $7.50 \pm 0.91^{\mathrm{a}}$ & $7.47 \pm 0.80^{\mathrm{a}}$ \\
& $(2.62)$ & $(2.98)$ \\
2.0 & $5.21 \pm 1.08^{\mathrm{b}}$ & $4.96 \pm 0.81^{\mathrm{b}}$ \\
& $(2.83)$ & $(3.04)$ \\
5.0 & $\mathrm{ND}^{*}$ & $3.99 \pm 0.10^{\mathrm{bc}}$ \\
& $(4.37)$ & $(3.20)$ \\
10.0 & $\mathrm{ND}^{*}$ & $1.87 \pm 0.12^{\mathrm{c}}$ \\
& $(5.29)$ & $(3.47)$ \\
\hline
\end{tabular}

Distinct lowercase letters in the same column indicate significant differences between different concentrations of CaGP (ANOVA and Tukey's test and Kruskal-Wallis and Dunn's test, respectively, for Coca-Cola ${ }^{\mathrm{TM}}$ and Sprite Zero $\left.^{\mathrm{TM}}, \mathrm{p}<0.05\right), \mathrm{n}=20$

*ND-not detectable reading. 
for Sprite $Z^{2}{ }^{T M}$, respectively.

As can be seen in Table 1, for both drinks, significant differences in the wear were found for the distinct concentrations of CaGP $(F=27.67$, $\mathrm{p}<0.0001$ for Coca-Cola ${ }^{\mathrm{T}}$ and $\mathrm{KW}=45.13, \mathrm{p}<0.0001$ for Sprite Zero $^{\text {TM }}$ ). A dose-response effect could be observed for both soft drinks. CaGP concentrations of $2 \mathrm{mM}$ or higher significantly reduced the enamel wear both for Coca-Cola ${ }^{\mathrm{Tm}}$ as for Sprite Zero ${ }^{\mathrm{Tm}}$ $(p<0.01)$ when compared to the control group.

CaGP added to Coca-Cola ${ }^{\mathrm{Tm}}$ at 5 and $10 \mathrm{mM}$ completely prevented erosion, since no wear could be detected. As for Sprite Zero ${ }^{T m}$, the highest CaGP concentration tested $(10 \mathrm{mM})$ reduced the wear by $75 \%$, but it was still detectable $(1.87 \pm 0.12 \mu \mathrm{m})$.

\section{DISCUSSION}

The degree of saturation of the beverages with respect to hydroxyapatite is very important when considering their erosive potential. It has been demonstrated that the presence of a degree of saturation with respect to hydroxyapatite of 0.032 , which can be achieved by adding $7.4 \mathrm{mM}$ of $\mathrm{Ca}$ and $0.6 \mathrm{mM}$ of phosphate to a solution of $10.1 \mathrm{mM}$ citric $(\mathrm{pH} 3.6)$, can reduce the time of softening of enamel in the solution by about $50 \%{ }^{3}$.

Due to the above-mentioned reason, in the present study the erosive potential of the soft drinks was evaluated after their supplementation with CaGP, which theoretically could be a source both of calcium and phosphate. However, in the CaGP molecule, phosphate is covalently bound to glycerol and is not expected to be released from the formulation in vitro in the absence of phosphatases. Despite this, phosphate might have played a role on the reduction of the erosive capacity of the soft drink due to its buffering capacity, as can be inferred from the $\mathrm{pH}$ measurements (Table 1 ). For Coca-Cola ${ }^{\mathrm{T}}$, at CaGP concentrations of 5.0 and $10 \mathrm{mM}$, the $\mathrm{pH}$ increased to 4.37 and 5.29, respectively, which, in combination with higher calcium concentrations, led to no detectable wear in enamel blocks. The effect of calcium alone was also evident, since CaGP at $2 \mathrm{mM}$ also was able to significantly reduce wear, for both soft drinks, despite only minor increases in the beverages $\mathrm{pH}$. Nevertheless, for higher concentrations of CaGP, the protective effect against erosion was more pronounced for Coca-Cola ${ }^{\mathrm{T}}$ when compared to Sprite Zero ${ }^{\mathrm{Tm}}$. This might have been due to several factors. The increases in $\mathrm{pH}$ after supplementation were much less pronounced for Sprite Zero ${ }^{\mathrm{Tm}}$. This might have been due to the presence of citric acid in this beverage, since it has been reported that citric acid $\left(\mathrm{CitH}_{3}\right)$ is capable of forming chelating complexes with calcium leading to a drop of $\mathrm{pH}$ due to the release of $\mathrm{H}^{+(1)}$.
In the study by Magalhães, et al. ${ }^{13}$ (2009), calcium at $1 \mathrm{mM}$ was able to significantly reduce the enamel wear caused by immersion in Sprite Zero $^{\mathrm{Tm}}$, regardless the presence of fluoride. Additionally, in the same study, the simultaneous addition of calcium and phosphate (both at $1 \mathrm{mM}$ ) to Sprite Zero $^{\mathrm{TM}}$ was not able to reduce enamel wear when compared to control (pure Sprite Zero ${ }^{T m}$ ). Those authors hypothesized that these ions reacted with each other within the beverage, thus reducing the amount of "free" ions to react with apatite. In the present study, the erosive challenge was much higher $(4 \times 10 \mathrm{~min})$ than the one employed by Magalhães, et al. ${ }^{13}$ (2009) (6x1 min). This might be the reason why CaGP was only effective in reducing enamel erosion for concentrations of $2 \mathrm{mM}$ or more. In the CaGP molecule, however, calcium is ionically linked to phosphate, while phosphate is covalently linked to glycerol. This might have prevented calcium from reacting with phosphate within the soft drinks, allowing free calcium ions to protect enamel against erosion and phosphate ions that could bind to protons from the soft drinks, increasing their $\mathrm{pH}$. Thus, it is possible that in the clinical situation, phosphate ions can be released by salivary phosphatases, thus altering the performance of CaGP when compared with the in vitro condition tested.

In conclusion, the supplementation of beverages with CaGP seems to be a viable alternative to reduce the erosive potential of the soft drinks, since it did not alter the taste of the drink. Only a slight difference in flavor was noticed in the groups containing the highest concentrations of CaGP. This is very important from a commercial point of view. Another advantage of the supplementation with CaGP is that it is completely safe, since even the highest doses tested in this study $(0.4 \mathrm{mg} / \mathrm{L}$ of calcium and $0.31 \mathrm{mg} / \mathrm{L}$ of phosphorus) are far below the maximum level of daily intake that is likely to pose no risk of adverse effects for both calcium $(2,500 \mathrm{mg} /$ day $)$ and phosphorus $(3,000 \mathrm{mg} / \text { day })^{4}$.

\section{ACKNOWLEDGEMENTS}

The authors thank PIBIT/CNPq/USP for the concession of a scholarship to the first author.

\section{REFERENCES}

1- Attin T, Barlage D, Buchalla W, Hannig C, Becker K. Dentine erosion by two citric acid concentrations with varying amounts of calcium. Caries Res. 2004;38:389.

2- Attin T, Meyer K, Hellwig E, Buchalla W, Lennon AM. Effect of mineral supplements to citric acid on enamel erosion. Arch Oral Biol. 2003;48(11):753-9.

3- Barbour ME, Parker DM, Allen GC, Jandt KD. Human enamel erosion in constant composition citric acid solutions as a function of degree of saturation with respect to hydroxyapatite. J Oral Rehabil. 2005;32(1):16-21. 
4- Food and Nutritional Information Center - FNIC [homepage]. Local: United States of America. Department of Agriculture: Washington, DC; c2009 [cited Aug 17 2011]. Available from: http://fnic.nal.usda.gov/nal_display/index.php?info_ center $=4 \&$ tax_level $=1$

5- Gerrard WA, Winter PJ. Evaluation of toothpastes by their ability to assist rehardening of enamel in vitro. Caries Res. $1986 ; 20(3): 209-16$.

6- Grenby T. Lessening dental erosive potential by product modification. Eur J Oral Sci. 1996;104:221-8.

7- Grenby TH, Bull JM. Use of high-performance liquid chromatography techniques to study the protection of hydroxylapatite by fluoride and glycerophosphate against demineralization in vitro. Caries Res. 1980;14(4):221-32.

8- Hughes JA, West NX, Addy M. The protective effect of fluoride treatments against enamel erosion in vitro. J Oral Rehabil. 2004;31(4):357-63.

9- Instituto Brasileiro de Geografia e Estatística - IBGE. Pesquisa de orçamentos familiares 2002-2003: Brasil e grandes regiões. Rio de Janeiro: IBGE; 2004.
10- Järvinen VK, Rytömaa, II, Heinonen OP. Risk factors in dental erosion. J Dent Res. 1991;70(6):942-7.

11- Kato MT, Italiani FM, Araújo JJ, Garcia MD, Sales-Peres SHC Buzalaf MA. Preventive effect of an iron varnish on bovine enamel erosion in vitro. J Dent. 2009;37(3):233-6.

12- Lynch RJ. Calcium glycerophosphate and caries: a review of the literature. Int Dent J. 2004;54:310-4.

13- Magalhães AC, Moraes SM, Rios D, Buzalaf MA. Effect of ion supplementation of a commercial soft drink on tooth enamel erosion. Food Addit Contam Part A Chem Anal Control Expo Risk Assess. 2009;26(2):152-6.

14- Mainwaring PJ, Naylor MN. A four-year clinical study to determine the caries-inhibiting effect of calcium glycerophosphate and sodium fluoride in calcium carbonate base dentifrices containing sodium monofluorophosphate. Caries Res. 1983;17(3):267-76. 15- Petersson GH, Bratthall D. The caries decline: a review of reviews. Eur J Oral Sci. 1996;104(4):436-43.

16- Vieira AE, Delbem AC, Sassaki KT, Rodrigues E, Cury JA, Cunha RF. Fluoride dose response in $\mathrm{pH}$-cycling models using bovine enamel. Caries Res. 2005;39(6):514-20. 